\title{
Congenital Segmental Intestinal Dilatation: A 25-Year Review with Long-Term Follow-up at the Medical University of Innsbruck, Austria
}

\author{
Consolato Sergi, MD, PhD, MPH, FRCPC, FCAP1,2,30 \\ Josef Hager, Prof. Mag. Phil. Dr. med. Univ. ${ }^{6}$ \\ ${ }^{1}$ Department of Orthopedics, Tianyou Hospital, Wuhan University of \\ Science and Technology, Wuhan, Hubei, P.R. China \\ ${ }^{2}$ Department of Laboratory Medicine and Pathology, University of \\ Alberta, Edmonton, Alberta, Canada \\ ${ }^{3}$ Department of Pediatrics, University of Alberta, Edmonton, Alberta, \\ Canada \\ ${ }^{4}$ Institute of Pathology, University Hospital of Essen, University \\ Duisburg-Essen, Essen, Germany \\ ${ }^{5}$ Institute of Pathology, Medical University of Innsbruck, Innsbruck, Austria \\ ${ }^{6}$ Department of Pediatric Surgery, Medical University of Innsbruck, \\ Innsbruck, Austria
}

Am J Perinatol Rep 2019;9:e218-e225.

\author{
Thomas Hager, $\mathrm{MD}^{4,5}$
}

Address for correspondence Consolato Maria Sergi, MD, PhD, MPH, FRCPC, FCAP, Department of Laboratory Medicine and Pathology, University of Alberta, 8440112 Street, Edmonton, AB T6G2B7, Canada (e-mail: sergi@ualberta.ca).
Abstract
Keywords
- dilatation
- intestine
- obstruction
- aganglionosis
- Hirschsprung's disease
- heart defect

Background and Aim Congenital segmental intestinal dilatation (CSID) is a neonatal condition with unclear etiology and pathogenesis. Typically, the newborn with CSID presents with a limited (circumscribed) bowel dilatation, an abrupt transition between normal and dilated segments, neither intrinsic nor extrinsic perilesional obstruction, and no aganglionosis or neuronal intestinal dysplasia. We aimed to review this disease and the long-term follow-up at the Children's Hospital of the Medical University of Innsbruck, Tyrol, Austria. Study Design Retrospective 25-year review of medical charts, electronic files, and histopathology of neonates with CSID.

Results We identified four infants (three girls and one boy) with CSID. The affected areas included duodenum, ileum, ascending colon, and sigmoid colon. Noteworthy, all patients presented with a cardiovascular defect, of which two required multiple cardiac surgical interventions. Three out of the four patients recovered completely. To date, the three infants are alive.

Conclusion This is the first report of patients with CSID and cardiovascular defects. The clinical and surgical intervention for CSID also requires a thorough cardiologic evaluation in these patients. CSID remains an enigmatic entity pointing to the need for joint forces in identifying common loci for genetic investigations.
Congenital segmental intestinal dilatation (CSID) is a neonatal condition with unclear etiology and pathogenesis. Typically, the newborn with CSID presents with a limited (1DConsolato Maria Sergi's ORCID is https://orcid.org/0000-0002-
2779-7879.

received

December 29, 2017

accepted after revision

April 26, 2019
DOI https://doi.org/

$10.1055 / \mathrm{s}-0039-1693164$. ISSN 2157-6998. (confined) bowel dilatation with three- to fourfold increase, an abrupt transition between normal and dilated segments, neither intrinsic nor extrinsic perilesional obstruction, and presence of normal ganglionic cells of the gastrointestinal autonomous plexus. ${ }^{1}$ There is no evidence of Hirschsprung's disease (aganglionosis) or neuronal intestinal dysplasia

Copyright @ 2019 by Thieme Medical Publishers, Inc., 333 Seventh Avenue, New York, NY 10001, USA. Tel: +1(212) 584-4662.
License terms

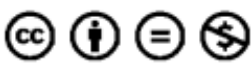


using the most updated laboratory diagnostic procedures. ${ }^{2-5}$ In some cases, a segmental absence of intestinal musculature may cause spontaneous bowel perforation, intestinal obstruction, or intussusception. ${ }^{6}$ The resection of the affected segment usually leads to complete recovery, but the clinical polymorphism and the lack of specificity of diagnostic imaging may point to the difficulty to have a complete preoperative picture of the disease. ${ }^{7,8}$

We aimed to review this disease and the long-term follow-up at the Children's Hospital of the Medical University of Innsbruck, Tyrol, Austria.

\section{Materials and Methods}

We reviewed the medical charts, electronic medical records, and histopathology at our institution (Children's Hospital, Innsbruck, Austria) of the Medical University of Innsbruck, Austria.

\section{Results}

We found four infants with CSID who underwent surgery at the Innsbruck Department of Pediatric Surgery. The clinical findings of the four infants (three girls and one boy) are shown in -Table 1, while the surgical sites and the histopathology findings are illustrated in - Figs. 1 and 2, respectively. Briefly, in the first patient, the affected area was the ascending colon. It was reduced by tapering and later used to close the colonic defect caused by atresia of the distal descending colon. The second patient had a dilated duodenum. The infant underwent to open exploratory surgery, and the duodenum was then tapered. The third infant had dilatation of the lower sigmoid colon, which was primarily resected, the rectum was closed, and an artificial anus was created in the sigmoid colon (sigmoidostomy). Six weeks later, a colostomy reversal was performed, and continuity was re-established by an end-toend anastomosis between the descending colon and rectum. The fourth infant had a dilated segment of the ileum which was resected, and an end-to-end ileoileostomy performed. In our patients, all histological findings showed data like the findings mentioned earlier. We found regular configured bowel wall segments with thin external muscle layers (-Fig. 2a-c). The pylorus tumor of patient 2 showed glandular structures lined by cuboidal to columnar epithelium surrounded by hypertrophic smooth muscle bundles, which corresponds to a gastric adenomyoma of the pylorus (-Fig. 2d). Ganglia cells were found in all specimens, although occasionally some ganglia cells were reported as immature.

Noteworthy, all patients presented with a cardiac/cardiovascular defect. Two of the four defects required multiple cardiac surgical interventions. Two patients had each an atrial septum defect and a ventricular septal defect (VSD), while the other two patients had complex congenital heart disease. Three patients recovered completely. To date, these

Table 1 Data of patients with CSID, associated anomalies, surgical interventions, and outcome

\begin{tabular}{|l|l|l|l|l|l|l|l|l|}
\hline Case & Sex & Year & Birth & BW & CSID & MCA & Surgery \\
\hline 1 & F & 1994 & $\begin{array}{l}\text { Term, } \\
\text { VD }\end{array}$ & 2,410 & $\begin{array}{l}\text { Ascending } \\
\text { colon }\end{array}$ & $\begin{array}{l}\text { High anal } \\
\text { atresia and } \\
\text { atresia of the } \\
\text { descending } \\
\text { colon, VUR III, } \\
\text { ASD }\end{array}$ & $\begin{array}{l}\text { (1) Tapering of ascending } \\
\text { colon, double-barreled } \\
\text { transverse loop colostomy } \\
\text { (2) Resection of the residual } \\
\text { descending colon, ascending } \\
\text { colon pull-through operation } \\
\text { (Soave) with the construction } \\
\text { of a neoanus }\end{array}$ & $\begin{array}{l}\text { Alive, uneventful, } \\
\text { apart from } \\
\text { pubertas praecox }\end{array}$ \\
\hline 2 & M & 1996 & $\begin{array}{l}\text { Term, } \\
\text { VD }\end{array}$ & 2360 & Duodenum & $\begin{array}{l}\text { Pyloric "tumor," } \\
\text { aortic arch } \\
\text { hypoplasia } \\
\text { (isthmus), IM }\end{array}$ & $\begin{array}{l}\text { Excision of the } \\
\text { tumor, tapering of the dilated } \\
\text { duodenal segment after } \\
\text { explorative duodenotomy }\end{array}$ & $\begin{array}{l}\text { Death after } \\
\text { cardiac surgery }\end{array}$ \\
\hline 3 & F & 1997 & $\begin{array}{l}\text { Term, } \\
\text { VD }\end{array}$ & 2,660 & Lower sigma & $\begin{array}{l}\text { Trisomy 21 } \\
\text { syndrome, VSD }\end{array}$ & $\begin{array}{l}\text { (1) Resection of the dilated } \\
\text { segment, blind rectum } \\
\text { closure, and terminal } \\
\text { sigmoidostomy } \\
\text { (2) End-to-end anastomosis } \\
\text { between } \\
\text { descending colon and rectum }\end{array}$ & $\begin{array}{l}\text { Alive, frequent } \\
\text { mechanical } \\
\text { dilatation of the } \\
\text { anastomosis } \\
\text { during the first 2 } \\
\text { y of life, growth } \\
\text { delay }\end{array}$ \\
\hline 4 & F & 2008 & $\begin{array}{l}39 t h, \\
\text { CS* }\end{array}$ & 3,700 & Ileum & $\begin{array}{l}\text { AVC, unroofed } \\
\text { CS, AAD, AL, } \\
\text { LCVP, left liver, IM }\end{array}$ & $\begin{array}{l}\text { Resection of dilated ileum } \\
\text { segment, } \\
\text { end-to-end ileoileostomy }\end{array}$ & $\begin{array}{l}\text { Alive, uneventful, } \\
\text { apart from } \\
\text { multiple (7) } \\
\text { CV operations }\end{array}$ \\
\hline
\end{tabular}

Abbreviations: AAD, arcus aortae dexter (right aortic arch); AL, arteria lusoria; ASD, atrial septal defect; AVC, atrioventricular channel; BW, birth weight (g); $\mathrm{CS}^{*}$, cesarean section; CS, coronary sinus; CSID, congenital segmental intestinal dilatation; CV, cardiovascular; IM, intestinal malrotation; LCVP, persistence of the left caval vein; VD, vaginal delivery; VSD, ventricular septal defect; VUR III, third degree of vesical-urethral reflux.

Notes: lleoileostomy is a surgical anastomosis between two segments of the ileum. The pyloric "tumor" was a gastric adenomyoma of the pylorus. Pathological examination revealed glandular structures lined by cuboidal to columnar epithelium surrounded by hypertrophic smooth muscle bundles. Gastric adenomyoma should be considered a differential diagnosis of hypertrophic pyloric stenosis and gastric duplication in newborns and children. 

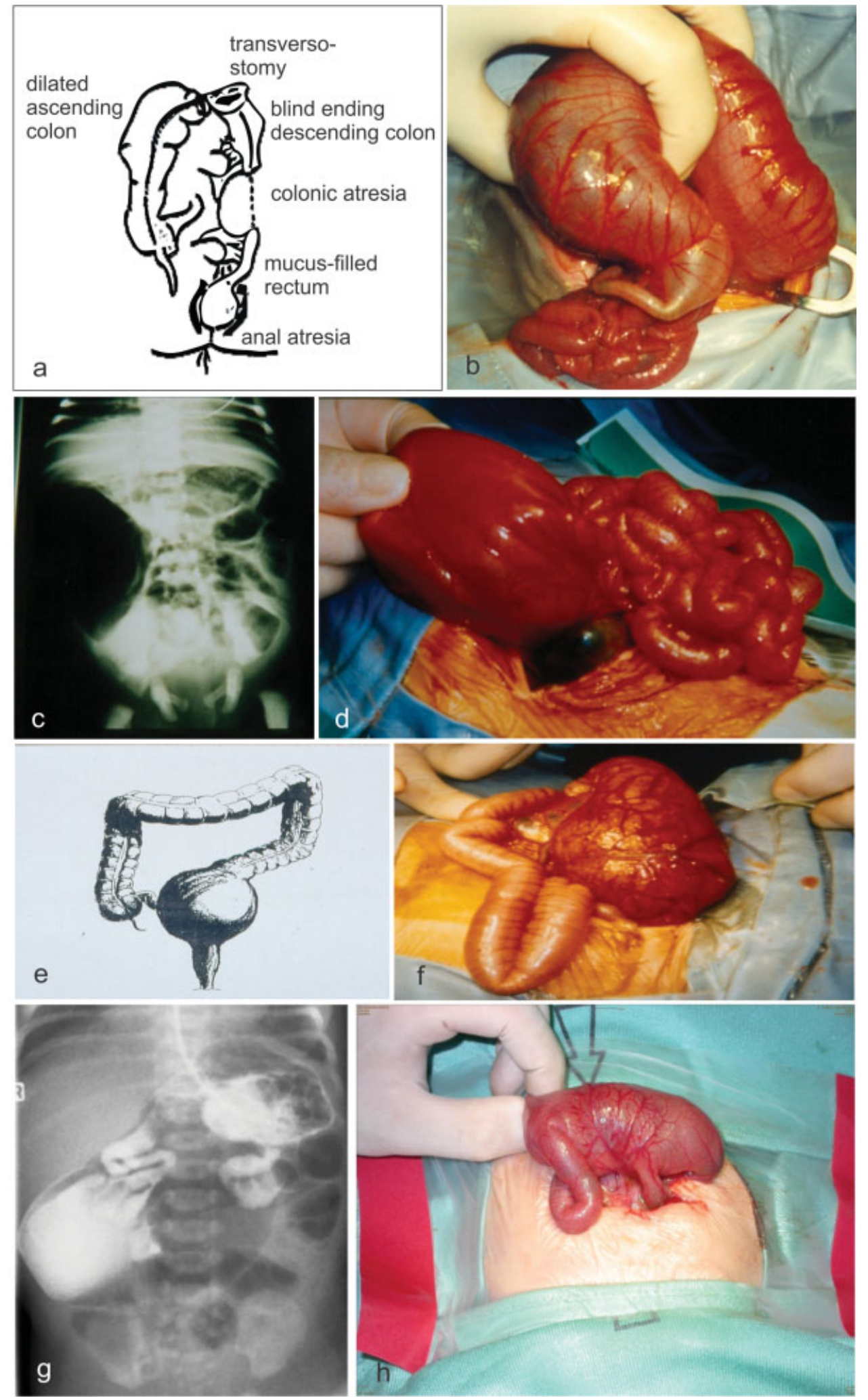

Fig. 1 (a) Patient 1: Scheme of the operation site with the malformations of the lower gastrointestinal tract (dilatation of the ascending colon, atresia of the descending colon, blindly closed rest of the sigmoid colon and the rectum, as well as anal atresia) after a double-barreled colostomy at the transverse colon. (b) Patient 1: Operative site of the CSID of the ascending colon. (c) Patient 2: Plain abdominal X-ray showing a sizeable gas-filled bowel loop in right upper abdominal quadrant. (d) Patient 2: Operative site of the mobile dilated duodenum. (e) Patient 3: Scheme of the circumscribed dilatation of the lowest part of the sigmoid colon. (f) Patient 3: Operative site of the dilated segment of the sigmoid colon (diameter of $10 \mathrm{~cm}$ ), the oral colon with standard configuration. (g) Patient 4: Upper gastrointestinal X-ray series showing pooling of the contrast media in a dilated loop of the ileum in the right hemiabdomen. (h) Patient 4: Intraoperative photograph of an 18-cm-long segmental dilatation of the middle ileum. The arrow in (h) points to the segmental dilatation of the portion of the intestine. The transition of normal bowel on both ends did not show any sign of mechanical obstruction. CSID, congenital segmental intestinal dilatation. 

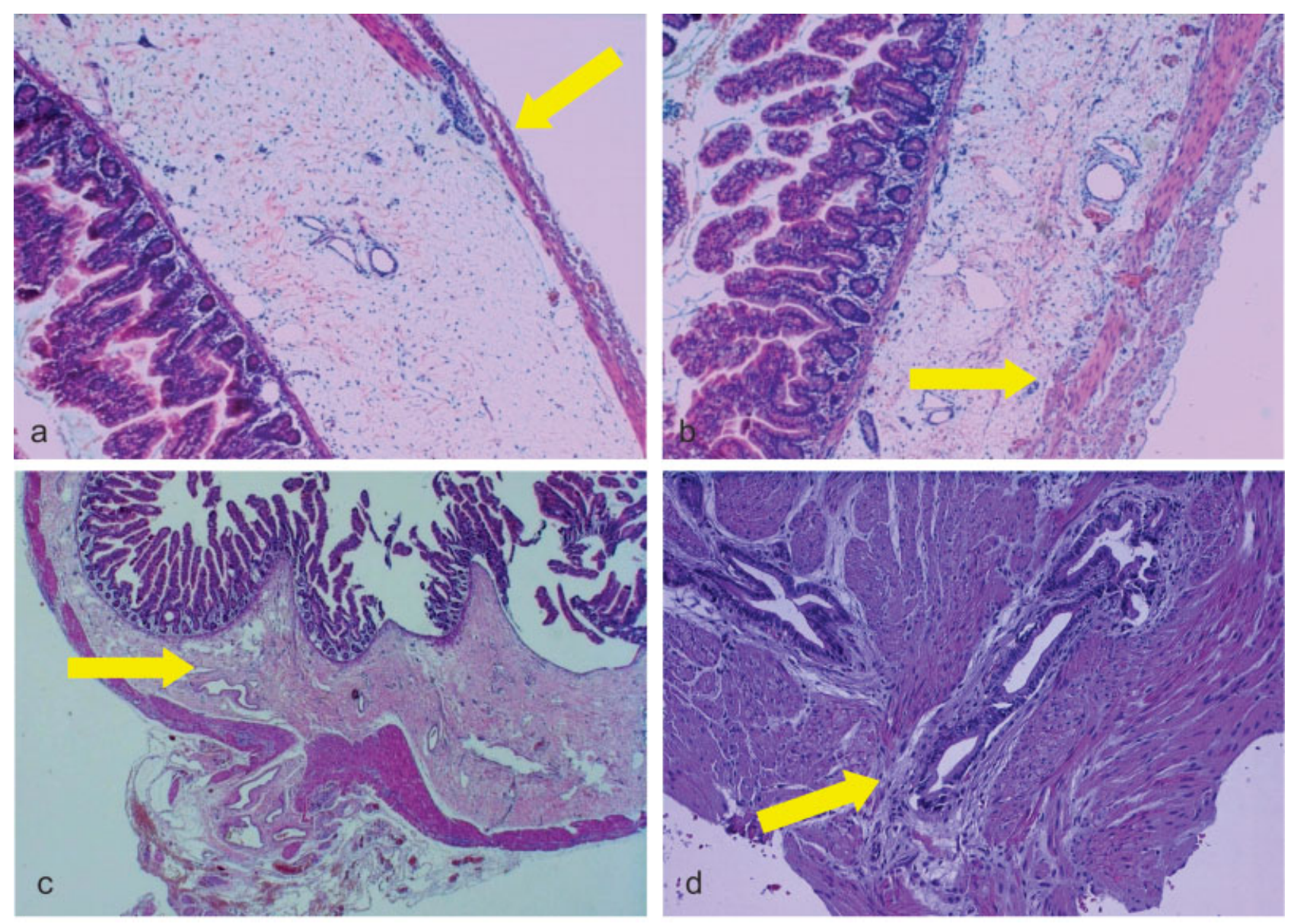

Fig. 2 (a, b) Microphotograph of CSID (Patient 4) with thin external muscle layer (hematoxylin and eosin $\times 40$ ) and dilated lymphatic vessels of the submucosa (hematoxylin and eosin staining, $\times 40$ original magnification); (c) microphotograph of CSID (Patient 3 ) showing sclerosis of the submucosa (hematoxylin and eosin staining, $\times 20$ original magnification); and (d) microphotograph of the "pyloric tumor" showing hypertrophic muscle layers with some scattered glandular proliferations corresponding to a gastric adenomyoma of the pyloric region (hematoxylin and eosin staining, $\times 100$ original magnification). The yellow arrows in (a) and (b) point to the very thin muscularis propria, while the yellow arrows in (c) and (d) point to the sclerosis of the submucosa and to the gastric adenomyoma of the pylorus, respectively. The gastric adenomyoma of the pylorus is characterized by glandular structures lined by cuboidal to columnar epithelium surrounded by hypertrophic smooth muscle bundles by histological examination. CSID, congenital segmental intestinal dilatation.

three infants are alive. One patient died of cardiac surgery complications.

\section{Discussion}

CSID has been defined as a circumscribed dilatation of the lumen with an abrupt transition between normal and dilated bowel and neither intrinsic nor extrinsic barrier distal of the dilatation. There is a sharply defined and markedly enlarged segment of the intestine flanked by normal caliber afferent and efferent bowel segments. ${ }^{7}$ CSID can involve the gastrointestinal tract anywhere from duodenum to the distal colon. The ileum and colon are the most commonly affected sites, while duodenum and jejunum are less frequently involved (Swenson and Rathauser [1959] [colon], Rossi and Giacomoni [1973] [jejunum], Sjölin and Thoren [1962] [ileum], Ueda and Okamoto [1972] [ileum], Irving and Lister [1977] [ileum], and Rovira et al [1989] [duodenum]). ${ }^{7,9-13}$ Since the entity may be described differently, the precise number of all published cases of CSID may be challenging to identify. In consideration of it, Ben Brahim et al reported 125 literature cases of CSID published up to $2006^{1}$ and added eight of their own, of which seven were newborn. However, Elemen et $\mathrm{al}^{14}$ indicated 2 years later that "slightly more than 100 cases" have been reported up to 2008 . It seems that there are $\sim 110$ to 120 cases adequately reported in around 50 years of reviewed literature. In consideration of the number of cases reported in the literature, two to three cases may present to the clinical attention yearly. In the last couple of decades, the criteria became stricter and, since 2008, to the best of our knowledge, 20 adequately described cases have been reported in the English literature. ${ }^{14-32}$ Here, we report on four infants with CSID with segmental dilatation located in the duodenum, ileum, ascending colon, and sigmoid colon. Two of our infants showed additional intestinal anomalies, but remarkably, all four patients had cardiovascular defects, and this is the first report demonstrating such a consistent association in four consecutive cases. In the review of the CSID cases, it is manifest that the associated malformations, which are found in more than $50 \%$ of the cases, are quite 
diverse, although the gastrointestinal tract and the omphalomesenteric duct are mostly involved. ${ }^{12,13,33-39}$

Histopathological findings of cases described in the literature range from partial or complete absence of lamina propria in the affected segment to partial hypertrophy of muscle layers with or without an irregular muscular network, minimal thinning of the external muscle layer, degenerated myocytes filled with vacuoles, and distended submucosal vessels up to angiodysplasia. ${ }^{12,13,28,40-45}$ In most cases, the histology of the resected segment is normal. Occasionally, a supernumerary intestinal muscle coat in the dilated segment, without any evidence of neurological abnormality, was observed. Histopathological findings of the resected ileal portion are reported to discuss the role of developmental malformation of muscularis propria as a cause of CSID. ${ }^{46}$ The presence of ganglion cells was reported in all cases of CSID as part of the criteria. Cheng et al performed an extended histochemical and immunohistochemical analyses of one instance of a jejunal CSID and postulated that segmental dilatations of the small bowel might not be in origin of the enteric nervous system but accuse a localized myopathy of the smooth muscle of being at least part of the sources of this entity. ${ }^{40} \mathrm{~A}$ differential diagnosis may reside in a segmental aganglionosis, an entity which is controversially discussed in the literature. ${ }^{47-49}$ In the case reported by Soyer et al, ${ }^{46}$ a 3 -day-old male neonate presenting with clinical findings of intestinal obstruction was diagnosed to have CSID and had supernumerary intestinal muscle coat in the dilated segment, without any evidence of neurological abnormality. Histopathological findings identify a striking similarity to our cases with duodenum dilatation or colon dilatation with anal atresia.

Other than hypertrophic or very thin muscle layers in the involved segment, ectopic tissue, such as the gastric or pancreatic tissue, was demonstrated. ${ }^{8,27,50}$ Gastric adenomyoma of the pyloric region should be considered a differential diagnosis of hypertrophic pyloric stenosis and gastric duplication in newborns and children. ${ }^{51,52}$

Nonspecific inflammatory or erosive changes can also occur. In the case reported by Elemen et al, erosive changes and nonspecific inflammation of the lamina propria were also found. ${ }^{14}$

In consideration of the clinical and histological presentations, it is unlikely to have only one pathogenesis for this condition. Three theories are frequently postulated, including the theory of Irving and Lister (1977), ${ }^{12}$ the theory of Mathé et al (1982), ${ }^{53}$ and the theory of Heller and Waag (1987). ${ }^{54}$ Irving and Lister suggested embryological damages implicate an extrinsic intrauterine intestinal compression with the intestine being strangulated by an umbilical ring, vitelline blood vessels, or omphalomesenteric bands. ${ }^{12}$ Mathe et al suggested a primitive (embryonic) neuromuscular dysfunction of the intestine, ${ }^{53}$ while Heller and Waag focused on an early disturbance during splitting of the notochord from the entoderm. ${ }^{54}$ These last authors pointed out that parts of the entoderm remain adherent to the ectoderm with the organization of cysts and/or tubes impairing the healthy development of the spine and eliciting other associated defects. ${ }^{54}$
In consideration of the cardiovascular anomalies encountered in our patients, we may consider our CSID infants to be a part of combined developmental disorders rather than a separate entity. In consideration of the development of the gut muscle layers and identification of pancreatic islets at 12 weeks of embryonal age (crown-rump length of $8.8 \mathrm{~cm}$ ), we may expect that a developmental disorder limited to the gut may involve these infants at this age. In case of an associated cardiovascular defect, the time of embryonic damage should be located earlier. The time of susceptibility for the development of atrial septal defect, VSD, aortic arch hypoplasia/coarctation of the aorta, and atrioventricular septal defects occurs between 6- and 8-week postfertilization. Thus, the insult should be prolonged enough to reach the 12 th week of postfertilization age. ${ }^{55}$ Congenital defects of the cardiovascular system are among the most common congenital birth defects estimated to occur in $\sim 1$ in 100 living births. ${ }^{56}$ Congenital malformations of the gut, urinary, and musculoskeletal systems are the most frequently seen extracardiac defects in patients with congenital defects of the cardiovascular system. ${ }^{57}$ Intestinal malrotation has been observed in 2.8 to $4.1 \%$ of all the patients with congenital defects of the cardiovascular system. ${ }^{58,59}$ In embryogenesis, the gut is developed at a later stage than the cardiovascular system does. Changes in intra-abdominal space caused by congenital heart defects might also increase the risk of abnormal gut development during embryogenesis. ${ }^{60,61} \mathrm{~A}$ common genetic cause might be another explanation in our patients. The left-right asymmetry is present in both the gut and the heart, and a specific biochemical cascade during embryogenesis has been demonstrated. ${ }^{62}$ Nodal growth differentiation factor (NODAL) and paired-like homeodomain 2 transcription factor 2 isoform c (PITX2c) are two signaling molecules derived from NODAL and PITX2c genes. Both NODAL and PITX2c are inevitable for this cardiac and gastrointestinal asymmetry and hypertrophy of the cardiomyocytes. ${ }^{63}$ In animal studies, an abnormal (reduced, diffuse, or absent) expression of PITX2c in the embryo causes abnormal looping from both heart and gut, ${ }^{64-67}$ resulting mainly in abnormal outflow tract orientation (e.g., unseptated and misaligned great artery trunks, double outlet right ventricle, symmetrical outflow tract cushions, and common atrioventricular trunk). ${ }^{65,66}$ The disturbance of the expression of PITX2c could cause a spectrum of isomerism. ${ }^{68}$

Concerning the diagnosis, there are challenges both during pregnancy and in the postpartum. CSID can either become symptomatic during the intrauterine life or after birth. However, the opinion that a CSID in the newborn is associated with subileus or ileus is not always correct. Depending on the extent of the enlargement, the intestinal transit is more or less affected, which means that a CSID can be entirely asymptomatic explaining the report of cases in older children. CSID is a malformation that becomes symptomatic at any age or even is an incidental finding at laparotomy. ${ }^{10,14,69}$ As a CSID can already become symptomatic in a fetus and/or in a newborn, a wide range of possibilities arises regarding diagnostics. To date, prenatal diagnosis has also increasingly diagnosed minor cystic changes in the 
abdomen of fetuses, for example, duodenal atresia, meconium ileus, intestinal duplication, and mesenteric cyst. The problem that arises is that while these structures are usually easy to recognize, they often cause diagnostic challenges when associated with CSID. Apart from a single case diagnosed prenatally, CSID is most commonly identified after birth because of the inaccuracy of the fetal intestinal echography. Paradiso et $\mathrm{al}^{19}$ found that two of their patients had a prenatal ultrasonographic suspicion of intestinal abnormality, which was confirmed in postpartum surgery.

However, the diagnosis of a CSID is not easy even postpartum, mainly if other intestinal malformations are associated. The clinical polymorphism and the glazing nonspecificity of radiological investigations complicate the diagnostic procedure. This entity remains enigmatic and challenging because of the ambiguous clinical findings, nonspecific radiological examinations, and mimickers of the urinary tract. ${ }^{50,70}$

In our four patients, two patients had ileal symptoms, and an exploratory laparotomy was scheduled on the second postpartum day (after deriving the gastric contents via a nasogastric tube). In the third patient, a cystic structure was detected in the fetus in the pelvis as part of sonographic pregnancy monitoring, but an assignment was not made. In the postnatal period, Hirschsprung's disease was suspected, although the megacolon appeared "spherical." Only in the fourth newborn could the prenatal diagnosis of a presumed cystic duplication be preoperatively revised in the direction of a CSID. Noteworthy, all four patients had congenital heart disease.

The relationship between CSID and heart failure remains to be questioned, although the occurrence of a heart defect in a child with trisomy 21 or with a high level of anal atresia is well known in the literature. Probably, the use of trisomy 16 mice, the animal model for human trisomy 21 , may be useful in the future.

The surgical procedure for correcting a CSID depends on its position. Most often, a segment resection in the sense of a onestep procedure with end-to-end anastomosis is possible. ${ }^{28,36,44,50,71-74}$ In our four patients, however, this was only possible in the third and fourth patients. In the third patient, because of the macroscopically unclear findings with suspicion of aganglionosis or neuronal intestinal dysplasia, such an approach was only feasible in two phases. Postoperative courses and outcomes, although dependent on the associated malformations, are mostly reported to be without complaints. 9,28,71 Regarding therapy, low-dose vasopressin may improve cardiac function as identified in previous experiments in newborn piglets with acute hypoxia-reoxygenation. ${ }^{75}$

In conclusion, CSID is a rare intestinal malformation, which can be associated with other anomalies, mostly of intestinal type. An association with cardiovascular defects should be considered an extreme rarity and may suggest that genetic counseling may be appropriate. The final diagnosis relies on the intraoperative picture and the exclusion of a segmental aganglionosis. Standard therapy is the total resection of the affected segment and end-to-end anastomosis or, depending on the position of the intestinal malformation, using specific surgical procedures. Postoperative course and outcome depend on the associated defects, but CSID itself is a condition which is mostly free of complications.

\section{Conflict of Interest}

None.

\section{References}

1 Ben Brahim M, Belghith M, Mekki M, et al. Segmental dilatation of the intestine. J Pediatr Surg 2006;41(06):1130-1133

2 Takawira C, D'Agostini S, Shenouda S, Persad R, Sergi C. Laboratory procedures update on Hirschsprung disease. J Pediatr Gastroenterol Nutr 2015;60(05):598-605

3 Burtelow MA, Longacre TA. Utility of microtubule associated protein-2 (MAP-2) immunohistochemistry for identification of ganglion cells in paraffin-embedded rectal suction biopsies. Am J Surg Pathol 2009;33(07):1025-1030

4 Chisholm KM, Longacre TA. Utility of peripherin versus MAP-2 and calretinin in the evaluation of Hirschsprung disease. Appl Immunohistochem Mol Morphol 2016;24(09):627-632

5 Yang WI, Oh JT. Calretinin and microtubule-associated protein-2 (MAP-2) immunohistochemistry in the diagnosis of Hirschsprung's disease. J Pediatr Surg 2013;48(10):2112-2117

6 Oyachi N, Suzuki T, Emura T, et al. Segmental absence of intestinal musculature with metachronous bowel perforations in an infant. J Pediatr Surg Case Rep 2018;30:1-3

7 Swenson O, Rathauser F. Segmental dilatation of the colon; a new entity. Am J Surg 1959;97(06):734-738

8 Porreca A, Capobianco A, Terracciano C, D'Onofrio V. Segmental dilatation of the ileum presenting with acute intestinal bleeding. J Pediatr Surg 2002;37(10):1506-1508

9 Rossi R, Giacomoni MA. Segmental dilation of the jejunum. J Pediatr Surg 1973;8(02):335-336

10 Sjolin S, Thoren L. Segmental dilatation of the small intestine. Arch Dis Child 1962;37:422-424

11 Ueda T, Okamoto E. Segmental dilatation of the ileum. J Pediatr Surg 1972;7(03):292-293

12 Irving IM, Lister J. Segmental dilatation of the ileum.J Pediatr Surg 1977;12(01):103-112

13 Rovira J, Morales L, Parri FJ, Juliá V, Claret I. Segmental dilatation of the duodenum. J Pediatr Surg 1989;24(11):1155-1157

14 Elemen L, Inanc D, Oz F, Erdogan E. Segmental dilatation of the ileum accompanying hypoproteinemia. J Pediatr Surg 2008;43 (07):e15-e18

15 Johnson L, Simone K, Cullen J, Talley A, Cohen EB. Radiographic features of congenital segmental dilation of the intestine in a German shepherd dog. Vet Radiol Ultrasound 2017. DOI: https:// doi.org/10.1111/vru.12581

16 Taguchi T, Ieiri S, Miyoshi K, et al. The incidence and outcome of allied disorders of Hirschsprung's disease in Japan: results from a nationwide survey. Asian J Surg 2017;40(01):29-34

17 Kaiser M, Castellani C, Singer G, Marterer R, Ratschek M, Till H. Huge congenital segmental dilatation of the sigmoid colon in a neonate: a "rarity to meet" and a "challenge to treat". Case Rep Pediatr 2016;2016:9685307

18 Rai BK, Mirza B, Hashim I, Saleem M. Varied presentation of congenital segmental dilatation of the intestine in neonates: report of three cases. J Neonatal Surg 2016;5(04):55

19 Paradiso FV, Coletta R, Olivieri C, et al. Antenatal ultrasonographic features associated with segmental small bowel dilatation: an unusual neonatal condition mimicking congenital small bowel obstruction. Pediatr Neonatol 2013;54(05):339-343

20 Sam CJ. Segmental ileal dilatation in a child. Trop Gastroenterol 2011;32(03):221-223

21 DeBenedet AT, Saini SD, Takami M, Fisher LR. Do clinical characteristics predict the presence of small bowel angioectasias on capsule endoscopy? Dig Dis Sci 2011;56(06):1776-1781 
22 Harjai MM, Katiyar A, Negi V, Yadav D, Sharma M. Congenital segmental dilatation of jejunoileal region in a newborn: unusual clinical and radiologic presentation. J Indian Assoc Pediatr Surg 2010;15(03):96-97

23 Inoue M, Uchida K, Otake K, Koike Y, Miki C, Kusunoki M. Congenital segmental dilatation of the duodenum: report of a case. Pediatr Int 2010;52(04):e184-e186

24 Okada T, Sasaki F, Honda S, et al. Disorders of interstitial cells of Cajal in a neonate with segmental dilatation of the intestine. J Pediatr Surg 2010;45(06):e11-e14

25 Shah AD, Kovanlikaya A, Beneck D, Spigland N, Brill PW. Segmental dilatation of the ileum in a healthy adolescent. Pediatr Radiol 2009;39(12):1350-1353

26 Saha S, Konar H, Chatterjee P, et al. Segmental ileal obstruction in neonates-a rare entity. J Pediatr Surg 2009;44(09):1827-1830

27 Brown BR, Hennessey I, Lansdale N, Humphrey G. Pancreatic tissue in congenital segmental dilatation of intestine: case presentation and recommendation for treatment. J Pediatr Surg 2008;43(11):e9-e11

28 Daher P, Ghanimeh J, Riachy E, Zeidan S, Eid B. Congenital segmental dilatation of the small bowel (CSD). Eur J Pediatr Surg 2007;17(04):289-291

29 Kella N, Rathi PK. Segmental defect of intestinal musculature: a rare cause of intestinal obstruction in children. J Coll Physicians Surg Pak 2006;16(08):551-552

30 Kothari P, Gowrishankar, Rastogi A, Dipali R, Kulkarni B; Gowrishankar. Congenital segmental dilatation of colon with colonic atresia. Indian J Gastroenterol 2005;24(03):123-124

31 Katsura S, Kudo T, Enoki T, Taguchi T, Hamano K. Congenital segmental dilatation of the duodenum: report of a case. Surg Today 2011;41(03):406-408

32 Mathur P, Mogra N, Surana SS, Bordia S. Congenital segmental dilatation of the colon with anorectal malformation. J Pediatr Surg 2004;39(08):e18-e20

33 Doody D, Nguyen LT. Congenital atresia of the colon combined with segmental dilatation of the ileum: a case report. J Pediatr Surg 1987;22(09):804-805

34 Ratcliffe J, Tait J, Lisle D, Leditschke JF, Bell J. Segmental dilatation of the small bowel: report of three cases and literature review. Radiology 1989;171(03):827-830

35 Ratan SK, Kulsreshtha R, Ratan J. Cystic duplication of the cecum with segmental dilatation of the ileum: report of a case. Surg Today 2001;31(01):72-75

36 Bell MJ, Ternberg JL, Bower RJ. Ileal dysgenesis in infants and children. J Pediatr Surg 1982;17(04):395-399

37 Brown RL, Azizkhan RG. Gastrointestinal bleeding in infants and children: Meckel's diverticulum and intestinal duplication. Semin Pediatr Surg 1999;8(04):202-209

38 Leinster SJ, Hughes LE. Segmental mega-ileum presenting as anaemia. Br J Surg 1981;68(06):417-419

39 Morewood DJ, Cunningham ME. Case report: segmental dilatation of the ileum presenting with anaemia. Clin Radiol 1985;36(03): 267-268

40 Cheng W, Lui VC, Chen QM, Tam PK. Enteric nervous system, interstitial cells of cajal, and smooth muscle vacuolization in segmental dilatation of jejunum. J Pediatr Surg 2001;36(06): 930-935

41 Huang SF, Vacanti J, Kozakewich H. Segmental defect of the intestinal musculature of a newborn: evidence of acquired pathogenesis. J Pediatr Surg 1996;31(05):721-725

42 Kuint J, Avigad I, Husar M, Linder N, Reichman B. Segmental dilatation of the ileum: an uncommon cause of neonatal intestinal obstruction. J Pediatr Surg 1993;28(12):1637-1639

43 Machens A, Thonke F, Kluth D, Lambrecht W. An unusual case of segmental dilatation of the sigmoid colon. Eur J Pediatr Surg 1997; 7(06):369-370

44 Mboyo A, Aubert D, Massicot R, Destuynder O, Lassauge F, Lorin A. Antenatal finding of intestinal obstruction caused by isolated segmental jejunal dilatation: a case report.J Pediatr Surg 1996;31 (10):1454-1456

45 Takahashi Y, Hamada Y, Taguchi T. Congenital segmental dilatation of the intestine. In: Puri P, eds. Pediatric Surgery. Berlin, Germany: Springer; 2017:1-7

46 Soyer T, Talim B, Tanyel FC. Segmental ileal dilatation with supernumerary intestinal muscle coat in a neonate. Surg Case Rep 2015;1(01):16

47 Bălănescu RN, Bălănescu L, Moga AA, Drăgan GC, Djendov FB. Segmental aganglionosis in Hirschsprung's disease in newborns - a case report. Rom J Morphol Embryol 2015;56(02): 533-536

48 Moore SW, Sidler D, Schubert PA. Segmental aganglionosis (zonal aganglionosis or "skip" lesions) in Hirschsprung's disease: a report of 2 unusual cases. Pediatr Surg Int 2013;29(05): 495-500

49 Martin LW, Buchino JJ, LeCoultre C, Ballard ET, Neblett WW. Hirschsprung's disease with skip area (segmental aganglionosis). J Pediatr Surg 1979;14(06):686-687

50 Kobayashi T, Uchida N, Shiojima M, et al. Segmental dilatation of the ileum covered almost entirely by gastric mucosa: report of a case. Surg Today 2007;37(12):1102-1104

51 Arslan EE, Demir TA, Güney LH, Tepeoğlu M, Akıllı MS, Hiçsönmez A. A rare case of a gastric adenomyoma mimicking a gastric duplication cyst. Turk J Gastroenterol 2018;29(05): 613-615

52 Takeyama J, Sato T, Tanaka H, Nio M. Adenomyoma of the stomach mimicking infantile hypertrophic pyloric stenosis. J Pediatr Surg 2007;42(11):E11-E12

53 Mathé JC, Khairallah S, Phat Vuoung NP, Boccon-Gibod L, Rey A, Costil J. [Segmental dilatation of the ileum in a neonate. Study of the myenteric plexus with a silver staining preparation (author's transl)]. Nouv Presse Med 1982;11(04):265-266

54 Heller K, Waag KL. [Formal genesis of segmental intestinal dilatation]. Langenbecks Arch Chir 1987;372:735-738

55 Hill MA. Embryology Paper-Teratogenicity in the setting of cardiac development and maldevelopment. Available at: https://embryology.med.unsw.edu.au/embryology/index.php/Paper_-_Teratogenecity_in_the_setting_of_cardiac_development_and_maldevelopment. Accessed March 1, 2019

56 Hoffman JI, Kaplan S. The incidence of congenital heart disease. J Am Coll Cardiol 2002;39(12):1890-1900

57 Calzolari E, Garani G, Cocchi G, et al; IMER Working Group. Congenital heart defects: 15 years of experience of the EmiliaRomagna Registry (Italy). Eur J Epidemiol 2003;18(08):773-780

58 Pradat P, Francannet C, Harris JA, Robert E. The epidemiology of cardiovascular defects, part I: a study based on data from three large registries of congenital malformations. Pediatr Cardiol 2003;24(03):195-221

59 Harris JA, Francannet C, Pradat P, Robert E. The epidemiology of cardiovascular defects, part 2: a study based on data from three large registries of congenital malformations. Pediatr Cardiol 2003;24(03):222-235

60 Torres AM, Ziegler MM. Malrotation of the intestine. World J Surg 1993;17(03):326-331

61 Kouwenberg M, Severijnen RS, Kapusta L. Congenital cardiovascular defects in children with intestinal malrotation. Pediatr Surg Int 2008;24(03):257-263

62 Beddington RS, Robertson EJ. Axis development and early asymmetry in mammals. Cell 1999;96(02):195-209

63 Essner JJ, Branford WW, Zhang J, Yost HJ. Mesendoderm and left-right brain, heart and gut development are differentially regulated by pitx2 isoforms. Development 2000;127(05): 1081-1093

64 Campione M, Steinbeisser H, Schweickert A, et al. The homeobox gene Pitx2: mediator of asymmetric left-right signaling in vertebrate heart and gut looping. Development 1999;126(06): $1225-1234$ 
65 Dagle JM, Sabel JL, Littig JL, Sutherland LB, Kolker SJ, Weeks DL. Pitx2c attenuation results in cardiac defects and abnormalities of intestinal orientation in developing Xenopus laevis. Dev Biol 2003; 262(02):268-281

66 Liu C, Liu W, Lu MF, Brown NA, Martin JF. Regulation of left-right asymmetry by thresholds of Pitx2c activity. Development 2001; 128(11):2039-2048

67 Ryan AK, Blumberg B, Rodriguez-Esteban C, et al. Pitx2 determines left-right asymmetry of internal organs in vertebrates. Nature 1998;394(6693):545-551

68 Logan M, Pagán-Westphal SM, Smith DM, Paganessi L, Tabin CJ. The transcription factor Pitx2 mediates situs-specific morphogenesis in response to left-right asymmetric signals. Cell 1998;94 (03):307-317

69 Javors BR, Gold RP, Ghahremani GG, et al. Idiopathic localized dilatation of the ileum in adults: findings on barium studies. AJR Am J Roentgenol 1995;164(01):87-90
70 Metcalfe PD, Bascom A, Sergi C. Mimickers and tumours in the lower urinary tract: do we need more efficient vigilance? Can Urol Assoc J 2013;7(5-6):E421-E425

71 al-Salem AH, Grant C. Segmental dilatation of the colon. Report of a case and review of the literature. Dis Colon Rectum 1990;33 (06):515-518

72 Brawner J, Shafer AD. Segmental dilatation of the colon. J Pediatr Surg 1973;8(06):957-958

73 Peña A, el Behery M. Megasigmoid: a source of pseudoincontinence in children with repaired anorectal malformations. J Pediatr Surg 1993;28(02):199-203

74 Ravasse P, Petit T, Cau D, Delmas P. Volvulus of the sigmoid colon as a complication of segmental dilatation of the colon. Report of 2 cases. Eur J Pediatr Surg 1996;6(06):375-377

75 Pelletier JS, LaBossiere J, Dicken B, et al. Low-dose vasopressin improves cardiac function in newborn piglets with acute hypoxiareoxygenation. Shock 2013;40(04):320-326 